proteins, it took a great deal of careful work to improve the quality of the crystals, and some ingenuity to determine their structure. Subtle changes in unit-cell dimensions occurred when the crystals were soaked to obtain heavy-metal derivatives necessary for phase determination. The authors finally resorted to a trick referred to as 'back soaking' to dislodge one of the heavy metals from its binding site. The problems associated with the unit-cell change could thus be avoided, and at last the structure was solved.

As with reports of every structure of a membrane protein - the total is now up to six - news that the structure of the bacterial light-harvesting complex has been solved will be greeted with the particular sense of excitement we feel when the curtain is finally raised on a long-awaited scene. The stage is now set for further revelations about the way in which living organisms make light work. $\square$

Werner Kühlbrandt is at the European Molecular Biology Laboratory, Meyerhofstrasse 1, 6900 Heidelberg, Germany.

\title{
Georges Köhler (1946-95)
}

ON 1 March Georges Köhler died of heart failure while suffering from pneumonia. He was only 48.

Together with César Milstein, Köhler invented the technique for producing monoclonal antibodies. This method uses the capacity of an antigen-activated normal B lymphocyte to produce and secrete one - and only one - antibody with a given specificity, and the ability of a tumour cell, the multiple myeloma or plasmocytoma, to proliferate without limits at the same stage of B-lineage development. Following fusion, the resulting so-called hybridoma grows like the tumour cell and secretes the monoclonal antibody in any desired quantity. In principle, this method allows the isolation and expansion in production of any antibody within the seemingly limitless and diverse repertoire of antibodies, present before or generated after challenge by an antigen in the immune system.

The generation of hybridomas is one of the most powerful inventions of the past 20 years. Monoclonal antibodies are rea. gents for the identification and purification of molecules and cells, both in basic research and in medicine. They have raised fresh hopes for Paul Ehrlich's idea that targeted antibodies can be used as magic bullets against infectious diseases and cancer. For inventing them, in 1984 Köhler and Milstein received the Nobel Prize in Physiology or Medicine, together with Niels Kaj Jerne who shared the prize for his theories concerning the specificity in development and control of the immune system.

As a PhD student of the University of Freiburg, Köhler studied the diversity of the immune response against the enzyme $\beta$-galactosidase in my laboratory at the Basel Institute for Immunology. In 1974 , when he finished his thesis, it was already known that single cells of the immune system produce only one type of antibody. But the genetic basis for this antibody diversity had not yet been discovered. Jerne, then director at the Basel Institute, had proposed that diver. sity might be generated by somatic mu. tations of a limited number of antibody genes transmitted from generation to generation. Köhler's plan was to study these mutations in antibody-producing cells by observing the clonal growth from one cell to thousands and millions of cells, all producing the same 'monoclonal' antibody. Unfortunately, however, normal antibody-producing cells grow only for a few divisions before they dietoo few to detect any changes in one of the cells in the clone.

Milstein's laboratory in Cambridge, UK, was one of the few where malignant

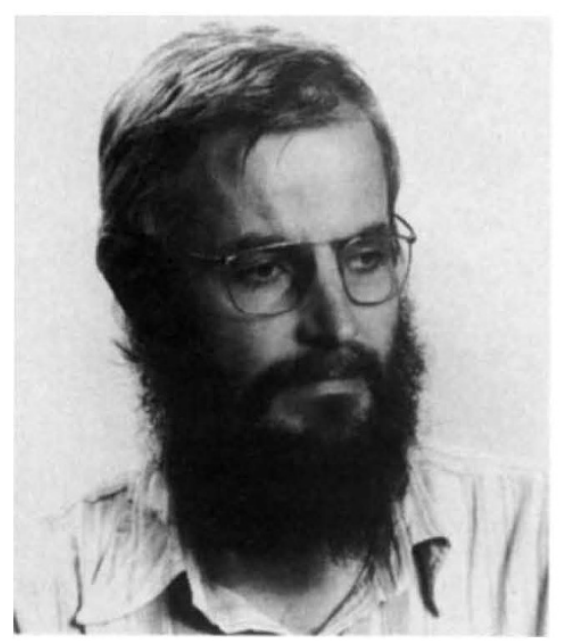

Georges Köhler - co-winner of a Nobel prize.

forms of these antibody-producing cells were grown in tissue culture, almost like bacteria, for unlimited periods of time. However, the antigen-binding specificity of the antibodies produced by the tumour cells was unknown. In 1974 Köhler received an EMBO fellowship to join Milstein's laboratory to look for mutations in antibody-producing cells. In long and lively discussions with Milstein, Köhler developed what he himself called the "crazy" idea of fusing a normal antibody-producing cell with a tumour cell at the same stage of development. He decided to use sheep erythrocytes as the antigen, because cells secreting antibody specific for this antigen could easily be detected as single cells in Jerne's haemolytic plaque assay.

He was lucky twice. First, he was fortunate to choose normal antibody. producing cells from a mouse that he had activated by immunization before his attempts at fusion. It turned out that the activated cells fuse 100 times better than non-activated cells, meaning that the chances of finding the desired hybridoma were likewise increased. The second stroke of luck was that the hybrid cells were stable and continued to produce antibody, in contrast to the results in previous fusion experiments by others. Never before had fusion partners kept the capacity to produce antibodies. Köhler's insight and good fortune gave him the cells to study how antibodies are made - a complex and exciting project which he pursued until his death.

In 1976, Köhler returned to the Basel Institute, where he continued his studies on the basic mechanisms of antibody generation and production in the cells of the immune system. Monoclonal antibodies have developed into a multibillion-dollar market, but neither Köhler nor Milstein participated in it. They did not patent the technique, nor did they found a company. Both of them remained dedicated to basic research. In 1985 Köhler left Basel to become director at the Max Planck Institute for Immunobiology in Freiburg. There he entered a second research area, the control of immune responses by cytokines.

Georges Köhler was devoted to science. He used his influence as a Nobel prizewinner to plead for the support of basic research motivated neither by commercial nor by other practical in. terests. He defended the freedom of science in society, and the principle of the need to know. When asked whether he didn't think it better to stop some research that could yield results which might have dangerous applications, he responded "Yes, we must control the applications of our results. But, safety by lack of knowledge: never!".

Whenever I remember Georges Köhler's life - with his family, in his laboratory, in his institute, in his collaborations with others, in the immunological community and in society - I am saddened and frustrated by the thought that he had to die so young, and much too soon.

Fritz Melchers

Fritz Melchers is at the Basel Institute for Immunology, Grenzacherstrasse 487, 4005 Basel, Switzerland. 